\title{
Guest-induced misfolding of a crown-ether-functionalized
} ortho-phenylene

\author{
Sumalatha Peddi, Molly C. Bookout, Gopi Nath Vemuri, and C. Scott \\ Hartley* \\ Department of Chemistry \& Biochemistry, Miami University, Oxford, Ohio \\ 45056, United States
}

\begin{abstract}
A crown-ether-functionalized $o$-phenylene tetramer has been synthesized and coassembled with monotopic and ditopic, achiral and chiral secondary ammonium ion guests. NMR spectroscopy shows that the o-phenylene forms both 1:1 and 1:2 complexes with monotopic guests while remaining well-folded. Binding of an elongated ditopic guest, however, forces the $o$-phenylene to misfold by pulling the terminal rings apart. A chiral ditopic guest biases the $o$-phenylene twist sense.
\end{abstract}

Inspired by the hierarchical structure of biomolecules, researchers are interested in the design of synthetic foldamers: oligomers that favor well-defined conformations because of noncovalent interactions (e.g., hydrogen bonding, arene-arene stacking, or backbone torsional

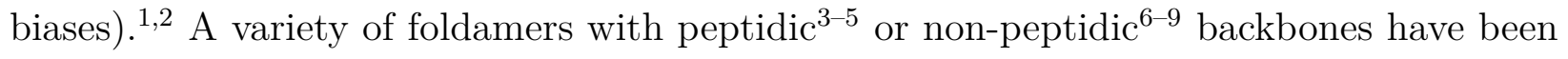
reported. Folding in these systems can be influenced by interactions with guest molecules. For example, many helical aromatic foldamers have central cavities for guest binding. ${ }^{10-14}$ Binding sites can also be introduced to folded systems through attachment of macrocycles to their 
exteriors. Voyer ${ }^{15-17}$ and Chen $^{18}$ have studied peptidic foldamers with crown ethers attached to their exteriors, which were successfully used as membrane ion channels. ${ }^{15}$ Similarly, Yashima, ${ }^{19,20}$ Kakuchi, ${ }^{21,22}$ and Nolte ${ }^{23}$ have appended crown ether binding sites to the exteriors of helical polymers; in many cases chiral guests induce a preferred twist sense. Abe and Inouye have merged interior and exterior binding in polymeric systems, demonstrating cooperative behavior. ${ }^{24}$

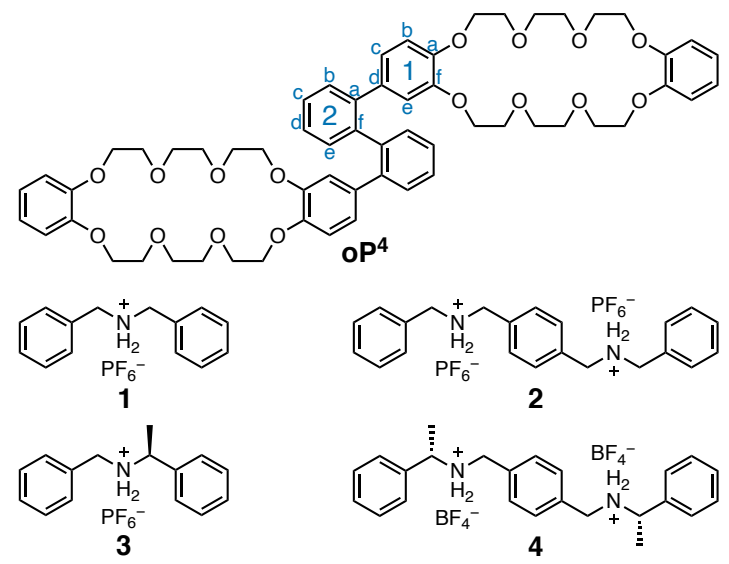

Chart 1: Crown-ether-functionalized ortho-phenylene tetramer $\mathbf{o P}^{4}$ and secondary amine guests $\mathbf{1}-\mathbf{4}$.

The $o$-phenylenes are a simple class of aromatic foldamers, adopting helical geometries with three repeat units per turn. ${ }^{25}$ A key feature of $o$-phenylenes is that their folding is easily perturbed because it is driven by (weak) arene-arene stacking interactions. ${ }^{26}$ It should therefore be possible to switch o-phenylene conformation through suitably designed host-guest binding, a potentially useful behavior for dynamic foldamer systems. ${ }^{27}$ o-Phenylenes lack an internal cavity that could bind guests, but their structure lends itself to incorporation of (benzo) crown ethers directly into their backbones. Here, we explore the effects of hostguest binding on short o-phenylene tetramer foldamers functionalized with crown ethers using the compounds in Chart 1 . We report the design and synthesis of dibenzo-24-crown8-functionalized $o$-phenylene $\mathbf{o P}^{\mathbf{4}}$, the changes in folding associated with the binding of monotopic and ditopic guests $\mathbf{1}$ and $\mathbf{2}$, and chiral induction through the binding of chiral guests 3 and 4 . 


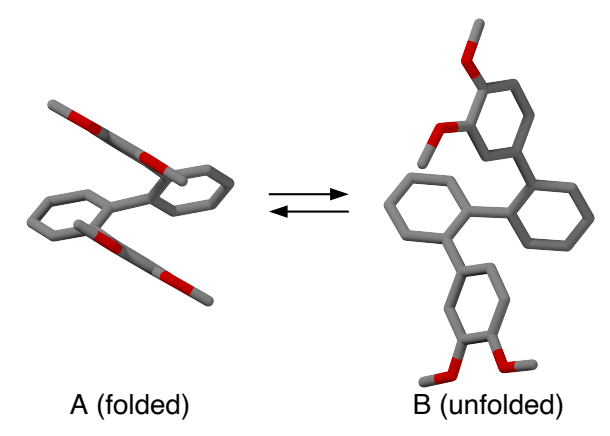

Figure 1: Conformers of $\mathbf{o P}^{\mathbf{4} \prime}$ optimized at the $\omega$ B97X-D/cc-pVDZ level (H atoms not shown).

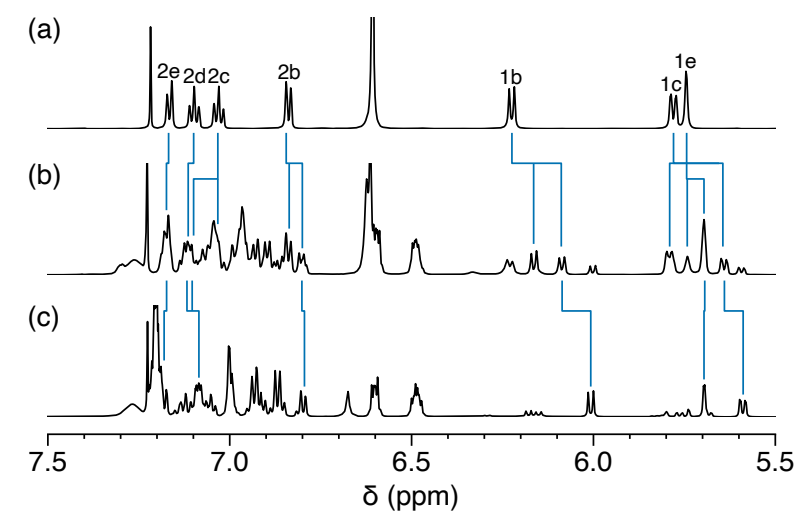

Figure 2: ${ }^{1} \mathrm{H}$ NMR spectra of (a) $\mathbf{o P}^{\mathbf{4}}$ and its (b) 1:1 (10 $\left.\mathrm{mM} \mathrm{oP}^{4}, 10 \mathrm{mM} \mathbf{1}\right)$ and (c) $1: 2$ (10 mM oP ${ }^{4}, 30 \mathrm{mM} \mathrm{1)} \mathrm{complexes} \mathrm{with} 1$ (600 MHz, 3:2 $\left.\mathrm{CDCl}_{3} / \mathrm{CD}_{3} \mathrm{CN}, 278 \mathrm{~K}\right)$.

Foldamer $\mathbf{o P}^{4}$ is expected to favor a helical conformation with one full turn, such that the two crown ethers will be stacked when folded but distant when misfolded. It has two possible backbone conformations that should exchange rapidly, shown in Figure 1 for $\mathbf{o P}^{\mathbf{4} \text {, a }}$ simplified model with the crown ethers replaced with methoxy groups. These two conformers differ in the torsional angle of the central biaryl bond (approximately $\pm 55^{\circ}$ for the "A" state and $\pm 135^{\circ}$ for the "B" state). ${ }^{25}$ The A conformer is a compact helix stabilized by one stacking interaction between the terminal rings and the $\mathrm{B}$ conformer is an extended helix without stabilizing aromatic stacking. Compound $\mathbf{o P}^{4}$ was prepared in a single step by Suzuki coupling of known 2,2'-dibromobiphenyl ${ }^{28}$ and the appropriate dibenzo-24-crown-8 boronic $\operatorname{acid}^{29}$ (Scheme S1).

We began host-guest studies by examining the interaction between guest $\mathbf{1}$ and $\mathbf{o P}^{\mathbf{4}}$. It 
is well-known that 1 forms a 1:1 complex with dibenzo-24-crown- 8 , stabilized by arene-arene stacking interactions and H-bonding. ${ }^{30}$ The complexed and uncomplexed species are in slow exchange on the NMR timescale. Thus, both 1:1 and 1:2 complexes are expected for the $\mathbf{o P}^{\mathbf{4}} / \mathbf{1}$ system. ${ }^{1} \mathrm{H}$ NMR spectroscopy titration experiments were carried out in $3: 2 \mathrm{CDCl}_{3} / \mathrm{CD}_{3} \mathrm{CN}$ at $278 \mathrm{~K}$ at a constant concentration of $\mathbf{o P}^{\mathbf{4}}(10 \mathrm{mM})$, varying the concentration of $\mathbf{1}$ (5-40 mM) (Figure S6). Representative ${ }^{1} \mathrm{H}$ NMR spectra are shown in Figure 2. New signals appear with increasing 1 that were assigned to the 1:1 and 1:2 complexes. All ${ }^{1} \mathrm{H}$ signals for the major species were assigned by using standard 2D NMR experiments (COSY, HSQC, HMBC) (Table S1). Signals corresponding to $\mathrm{H}_{1 \mathrm{~b}}$ (Chart 1) are particularly useful in distinguishing the different species as they are well-separated from the rest of the spectrum. Integration shows that the 1:1 and 1:2 complexes are the major species at 1:1 and 1:3 ratios of $\mathbf{o P}^{\mathbf{4}} / \mathbf{1}$, respectively.

The association constant for dibenzo-24-crown-8 and $\mathbf{1}$ has been previously determined to be on the order of $500 \mathrm{M}^{-1}{ }^{31}$ The apparent binding constants from the NMR titration experiments (Figures S38, S39) are concentration-dependent, as expected, ${ }^{31}$ but of the same order $\left(K_{1} \approx 500 \mathrm{M}^{-1}\right.$ for the $1: 1$ complex and $K_{2} \approx 100 \mathrm{M}^{-1}$ for subsequent binding in the 1:2 complex). We conclude that binding of monotopic guest $\mathbf{1}$ to host $\mathbf{o P}^{\mathbf{4}}$ is comparable to the parent system and in non-cooperative (since $K_{1}$ is approximately $4 K_{2}$ ). ${ }^{32}$

NMR chemical shifts provide important insight into the folding state of $o$-phenylenes in solution ${ }^{25}$ because geometry changes tend to move protons in and out of the shielding zones of nearby aromatic rings. In both the $1: 1$ and $1: 2$ complexes, the signals for $\mathrm{H}_{1 \mathrm{~b}}, \mathrm{H}_{1 \mathrm{c}}$, and $\mathrm{H}_{1 \mathrm{e}}$ of $\mathbf{o P}^{4}$ are shifted upfield, which is likely due to the shielding effect of $\mathbf{1}$. Protons on the internal rings $\left(\mathrm{H}_{2 \mathrm{~b}}-\mathrm{H}_{2 \mathrm{e}}\right)$ are far from the binding sites, but should be sensitive to changes in conformation. Their chemical shifts exhibit only small differences $(<0.1 \mathrm{ppm})$ between the uncomplexed and complexed states. We conclude that the binding of guest 1 to the crown ether functionalized tetramer in the 1:1 and 1:2 complexes does not substantially affect the folding of the $o$-phenylene. 


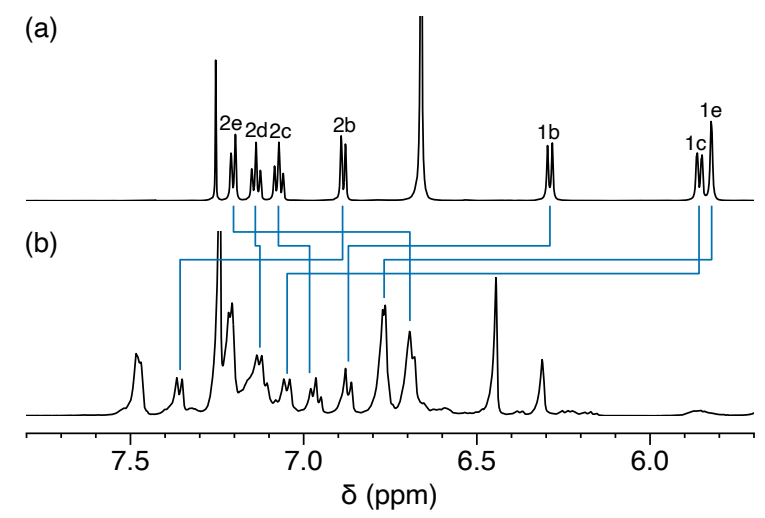

Figure 3: ${ }^{1} \mathrm{H}$ NMR spectra of (a) $\mathbf{o P}^{4}$ and (b) its 1:1 (2 $\left.\mathrm{mM} \mathrm{oP}^{4}, 2 \mathrm{mM} \mathbf{2}\right)$ complex with 2 $\left(500 \mathrm{MHz}, 3: 2 \mathrm{CDCl}_{3} / \mathrm{CD}_{3} \mathrm{CN}, 278 \mathrm{~K}\right)$.

We then conducted host-guest studies of host $\mathbf{o P}^{\mathbf{4}}$ with $\mathbf{2}$, which comprises two secondary ammonium ion centers. The 1:2 complex of ditopic guest 2 with dibenzo-24-crown- 8 has been reported. ${ }^{30}$ Since the $\mathbf{o P}^{\mathbf{4}}$ and $\mathbf{2}$ are both ditopic, we anticipated a twofold-symmetrical complex with the two ammonium ions in $\mathbf{2}$ simultaneously binding to the two crown-ethers in $\mathbf{o P}^{4}$. This expectation was confirmed by ${ }^{1} \mathrm{H}$ NMR titration experiments that were carried out with varying concentration of guest $(1-7 \mathrm{mM})$ and constant host concentration $(2 \mathrm{mM})$ at $278 \mathrm{~K}$ in $3: 2 \mathrm{CDCl}_{3} / \mathrm{CD}_{3} \mathrm{CN}$ (Figure S17). Figure 3 shows a representative spectrum. At sub-stoichiometric equivalents of $\mathbf{2}$, new signals corresponding to a single new species appear that were assigned to the 1:1 complex. With stoichiometric (or excess) 2, only signals assigned to the 1:1 complex are present along with signals from free $\mathbf{2}$, indicating that further complexation does not occur.

Binding in this system was clearly much stronger than with guest $\mathbf{1}$. To estimate the association constant, UV-vis titration experiments were performed at constant concentration of host $(0.1 \mathrm{mM})$ with varying concentration of guest $(0.01-1 \mathrm{mM})$ at $298 \mathrm{~K}$ in $3: 2$ $\mathrm{CHCl}_{3} / \mathrm{CH}_{3} \mathrm{CN}$ (Figure S35). As the concentration of 2 increases, the absorbance peak assigned to $\mathbf{o P}^{\mathbf{4}}$ at $310 \mathrm{~nm}$ gradually decreases, with an isosbestic point at $300 \mathrm{~nm}$. The overall association constant for the 1:1 complex of host $\mathbf{o P}^{\mathbf{4}}$ and guest $\mathbf{2}$ was estimated as $K=(9 \pm 4) \times 10^{5} \mathrm{M}^{-1}\left(25^{\circ} \mathrm{C}\right)$. Thus, binding between $\mathbf{o P}^{4}$ and $\mathbf{2}$ is approximately three orders of magnitude stronger than that between $\mathbf{o P}^{\mathbf{4}}$ and $\mathbf{1}$ because of the chelate effect. 
The ${ }^{1} \mathrm{H}$ NMR signals for the 1:1 complex could be assigned by using standard 2D NMR experiments (COSY, HSQC, HMBC) (Table S2 in SI). As shown in Figure 3, the chemical shifts of the protons on the internal rings $\left(\mathrm{H}_{2 \mathrm{~b}}-\mathrm{H}_{2 \mathrm{e}}\right)$ are significantly different in the complex compared to in the free host $\mathbf{o P}^{4}$, strongly suggesting that the conformation of the $o$-phenylene in the complex has changed. To confirm that NMR chemical shift changes are consistent with the expected changes in geometry, that is, correspond to a switch from the A to B states in Figure 1, isotropic shieldings were calculated for the A and B conformers of $\mathbf{o P}^{\mathbf{4} \prime}$ using DFT (see Supporting Information). The resulting predicted chemical shift differences between the $\mathrm{A}$ and $\mathrm{B}$ states of $\mathbf{o P}^{\mathbf{4}}\left(\delta_{\text {calc }}^{\mathrm{B}}-\delta_{\text {calc }}^{\mathrm{A}}\right)$ were compared with the experimental chemical shifts differences between the complex and free $\mathbf{o P}^{4}\left(\delta_{\text {exp }}^{\text {complex }}-\delta_{\text {exp }}^{\text {free host }}\right)$. The good linear correlation suggests that the host $\mathbf{o} \mathbf{P}^{4}$ is likely forced into the $\mathrm{B}$ conformer in the complex (Figure S23). That is, binding to 2 forces the outer rings of the $o$-phenylene apart. This is reasonable given the relative lengths of the species: the distance between the two $\mathrm{N}$ atoms in 2 is $7.5 \AA$, longer than the approximately $5 \AA$ separation between terminal rings in $\mathbf{o P}^{4}$ in the A state. ${ }^{33}$

After investigating the effect of o-phenylene folding with achiral guests $\mathbf{1}$ and $\mathbf{2}$, we examined twist-sense-induction from the binding of chiral guest 3. ${ }^{1} \mathrm{H}$ NMR experiments were carried out with guest 3 and host $\mathbf{o P}^{4}$ at $278 \mathrm{~K}$ in $3: 2 \mathrm{CDCl}_{3} / \mathrm{CD}_{3} \mathrm{CN}$ (Figure S24). Unfortunately, no evidence of binding was observed, presumably because of the added steric hindrance in $\mathbf{3}$ compared to $\mathbf{1}$.

Given the much stronger binding of $\mathrm{oP}^{4}$ to $\mathbf{2}$ compared to $\mathbf{1}$, we shifted our attention to ditopic chiral guest 4 (Chart 1) ${ }^{34}$ The formation of 1:1 complexes was confirmed by ${ }^{1} \mathrm{H}$ NMR titration experiments with varying concentration of $4(0.5-4 \mathrm{mM})$ at a constant concentration of $\mathbf{o P}^{4}(1 \mathrm{mM})$ at $278 \mathrm{~K}$ in $3: 2 \mathrm{CDCl}_{3} / \mathrm{CD}_{3} \mathrm{CN}$ (Figure S25). The resulting ${ }^{1} \mathrm{H}$ NMR spectra are complex because of the two diastereomeric 1:1 complexes that can be formed between $\mathbf{o P}^{4}$ and 4 . The signals for one of the complexes could be assigned by using standard 2D NMR experiments (COSY, HSQC, HMBC) (Table S3). The observed changes 


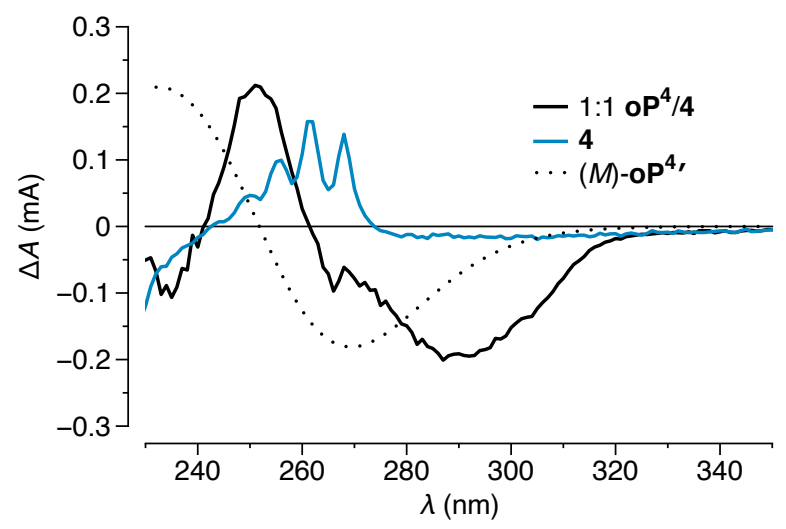

Figure 4: CD spectra of a 1:1 ratio of $\mathbf{o P}^{\mathbf{4}} / \mathbf{4}(1 \mathrm{mM})$ and $4(3 \mathrm{mM})$ alone $\left(3: 2 \mathrm{CHCl}_{3} / \mathrm{CH}_{3} \mathrm{CN}\right)$. The dotted line represents the predicted $\mathrm{CD}$ spectrum for $(M)-\mathbf{o P}^{\mathbf{4} \prime}$ in its B state (arbitrary units, TD/PCM $\left(\mathrm{CHCl}_{3} / \mathrm{CAM}-\mathrm{B} 3 \mathrm{LYP} / 6-31 \mathrm{G}(\mathrm{d}, \mathrm{p}) / / \omega \mathrm{B} 97 \mathrm{X}-\mathrm{D} / \mathrm{cc}-\mathrm{pVDZ}\right)$

in chemical shifts compared to free $\mathbf{o P}^{4}$ are consistent with those observed for binding to $\mathbf{2}$; that is, comparison of the chemical shifts to isotropic shielding calculations suggest that the o-phenylene must unfold on binding (Figure S31).

As shown in Figure 4, the addition of chiral guest 4 to $\mathbf{o P}^{\mathbf{4}}$ induces a negative Cotton effect at $290 \mathrm{~nm}$, a region where the $o$-phenylene absorbs but not 4 . The association constant was estimated by a titration experiment (Figure S37). The incremental addition of chiral guest 4 to a solution of $o$-phenylene tetramer $\mathbf{o P}^{4}$ results in the increase and eventual saturation of the CD signal. This is due to the formation of the 1:1 complex as the dominant species as seen with the achiral guest $\mathbf{2}$, consistent with the NMR results. The overall association constant for the 1:1 complex of host $\mathbf{o P}^{4}$ and guest 4 was determined to be $K=(4 \pm 2) \times$ $10^{4} \mathrm{M}^{-1}\left(5^{\circ} \mathrm{C}\right)$, about 20 -fold smaller than that for the binding of $\mathbf{o P}^{4}$ to $\mathbf{2}$.

TD-DFT predictions of the CD spectra of $\mathbf{o P}^{\mathbf{4} \prime}$ in its B state (dotted line in Figure 4) indicate that the binding to 4 likely favors the $M$ (left-handed) twist sense of the $o$-phenylene helix. Unfortunately, we could not identify NMR signals for the two o-phenylene twist senses that were sufficiently well-resolved to determine the diastereomeric excess (de) of the complex.

In summary, we have explored the effect of guest binding on $o$-phenylene folding. Binding of monotopic guest $\mathbf{1}$ to host $\mathbf{o P}^{\mathbf{4}}$ has little effect on the oligomer's conformation, which remains well-folded in its compact helical A state in both 1:1 and 1:2 complexes. Achiral 
ditopic guest 2 forms a much stronger 1:1 complex and forces the $o$-phenylene tetramer to misfold into an extended helical B state because of a mismatch between the separation of the ammonium groups in $\mathbf{2}$ and the crown ethers in $\mathbf{o P}^{\mathbf{4}}$. Chiral ditopic guest $\mathbf{4}$ forms an analogous 1:1 complex and generates an excess of the $M$ twist sense.

\section{Experimental}

\section{Synthesis}

Unless otherwise noted, all starting materials, reagents, and solvents were purchased from commercial sources and used without further purification. Melting points were determined using a Thermal Analysis Q20 differential scanning calorimeter at a heating rate of $10{ }^{\circ} \mathrm{C} / \mathrm{min}$. NMR spectra were measured for $\mathrm{CDCl}_{3}$ and $\mathrm{CD}_{3} \mathrm{CN}$ solutions using Bruker Avance 600 or $500 \mathrm{MHz}$ NMR spectrometers. The guest cations $\mathbf{1},{ }^{30} \mathbf{2},{ }^{30} \mathbf{3},{ }^{35}$ and $\mathbf{4}^{34}$ were synthesized according to literature procedures, as was 4-(4,4,5,5-tetramethyl-1,3,2-dioxaborolan-2-yl)dibenzo-24-crown-8. ${ }^{29}$

\section{$o$-Phenylene tetramer $\mathrm{oP}^{4}$}

An oven-dried Schlenk vacuum tube was charged with 2,2'-dibromobiphenyl ${ }^{28}$ (0.14 g, 0.45 mmol), 4-(4,4,5,5-tetramethyl-1,3,2-dioxaborolan-2-yl)-dibenzo-24-crown-8 ${ }^{29}$ (0.644 g, 1.12 mmol $), \mathrm{Pd}(\mathrm{OAc})_{2}(0.010 \mathrm{~g}, 0.045 \mathrm{mmol})$, SPhos (0.022 g, $\left.0.053 \mathrm{mmol}\right)$, and $\mathrm{K}_{3} \mathrm{PO}_{4}(0.285$ g, $1.35 \mathrm{mmol})$, then evacuated and back-filled with argon $(3 \times)$. To the tube was added degassed THF $(12 \mathrm{~mL})$ and deionized water $(3 \mathrm{~mL})$. The mixture was degassed by three freeze-pump-thaw cycles and then filled with argon. The reaction mixture was heated at 85-90 ${ }^{\circ} \mathrm{C}$ for $24 \mathrm{~h}$ (silicone oil bath), then cooled to room temperature and diluted with water $(10 \mathrm{~mL})$ and DCM $(5 \mathrm{~mL})$. The organic layer was separated and the aqueous layer extracted with DCM $(3 \times 5 \mathrm{~mL})$. The combined organic layers were washed with brine, dried over

$\mathrm{MgSO}_{4}$, filtered, and concentrated. Purification by flash chromatography on basic alumina 
(1:9 acetone:DCM), recrystallization $(\mathrm{MeOH})$, and chromatography on a C-18 column $(\mathrm{MeOH})$ gave compound $\mathbf{o P}^{4}$ as a white solid (0.132 g, 28\%): $\mathrm{mp} 118.86{ }^{\circ} \mathrm{C} ;{ }^{1} \mathrm{H}$ NMR $(600 \mathrm{MHz}$ 3:2 $\left.\mathrm{CDCl}_{3} / \mathrm{CD}_{3} \mathrm{CN}, 278 \mathrm{~K}\right) \delta 7.20(\mathrm{~d}, J=7.6 \mathrm{~Hz}, 2 \mathrm{H}), 7.14(\mathrm{t}, J=7.5 \mathrm{~Hz}, 2 \mathrm{H}), 7.08(\mathrm{t}, J=8.3$ $\mathrm{Hz}, 2 \mathrm{H}), 6.89(\mathrm{~d}, J=8.9 \mathrm{~Hz}, 2 \mathrm{H}), 6.66(\mathrm{~m}, 8 \mathrm{H}), 6.29(\mathrm{~d}, J=8.3 \mathrm{~Hz}, 2 \mathrm{H}), 5.86(\mathrm{~d}, J=8.3$ $\mathrm{Hz}, 2 \mathrm{H}), 5.83(\mathrm{~s}, 2 \mathrm{H}), 3.90-3.78(\mathrm{~m}, 12 \mathrm{H}), 3.65-3.61$ (m, 12H), 3.54-3.43 (m, 22H), 3.35-3.30 $(\mathrm{m}, 2 \mathrm{H}) ;{ }^{13} \mathrm{C}\left\{{ }^{1} \mathrm{H}\right\} \mathrm{NMR}\left(126 \mathrm{MHz}, 3: 2 \mathrm{CDCl}_{3} / \mathrm{CD}_{3} \mathrm{CN}, 278 \mathrm{~K}\right) \delta 147.8,146.5,146.0,139.6$, 139.2, 132.8, 130.5, 128.6, 126.7, 126.1, 120.7, 120.4, 113.3, 112.8, 111.7, 70.12, 70.09, 70.0, 68.9, 68.8, 68.6, 68.02, 68.00, 67.4; HRMS (ESI-Orbitrap) calcd for $\mathrm{C}_{60} \mathrm{H}_{70} \mathrm{NaO}_{16}{ }^{+} 1069.4556$ $\left(\left[\mathrm{M}+\mathrm{Na}^{+}\right]\right)$, found 1069.4513 .

\section{Acknowledgements}

We thank the National Science Foundation for support of this work (CHE-1608213 and CHE-1904236).

\section{References}

(1) Gellman, S. H. Foldamers: a manifesto. Acc. Chem. Res. 1998, 31, 173-180.

(2) Hill, D. J.; Mio, M. J.; Prince, R. B.; Hughes, T. S.; Moore, J. S. A field guide to foldamers. Chem. Rev. 2001, 101, 3893-4011.

(3) Martinek, T. A.; Fülöp, F. Peptidic foldamers: ramping up diversity. Chem. Soc. Rev. 2012, 41, 687-702.

(4) Reinert, Z. E.; Horne, W. S. Protein backbone engineering as a strategy to advance foldamers toward the frontier of protein-like tertiary structure. Org. Biomol. Chem. 2014, 12, 8796-8802.

(5) Wang, P. S. P.; Schepartz, A. $\beta$-Peptide bundles: Design. Build. Analyze. Biosynthesize. Chem. Commun. 2016, 52, 7420-7432. 
(6) Saraogi, I.; Hamilton, A. D. Recent advances in the development of aryl-based foldamers. Chem. Soc. Rev. 2009, 38, 1726-1743.

(7) Barboiu, M.; Stadler, A.-M.; Lehn, J.-M. Controlled folding, motional, and constitutional dynamic processes of polyheterocyclic molecular strands. Angew. Chem., Int. Ed. 2016, 55, 4130-4154.

(8) Zhang, D.-W.; Zhao, X.; Hou, J.-L.; Li, Z.-T. Aromatic amide foldamers: structures, properties, and functions. Chem. Rev. 2012, 112, 5271-5316.

(9) Laursen, J. S.; Engel-Andreasen, J.; Olsen, C. A. $\beta$-Peptoid foldamers at last. Acc. Chem. Res. 2015, 48, 2696-2704.

(10) Juwarker, H.; Suk, J.-m.; Jeong, K.-S. Foldamers with helical cavities for binding complementary guests. Chem. Soc. Rev. 2009, 38, 3316-3325.

(11) Ferrand, Y.; Huc, I. Designing helical molecular capsules based on folded aromatic amide oligomers. Acc. Chem. Res. 2018, 51, 970-977.

(12) Liu, Y.; Parks, F. C.; Sheetz, E. G.; Chen, C.-H.; Flood, A. H. Polarity-tolerant chloride binding in foldamer capsules by programmed solvent-exclusion. J. Am. Chem. Soc. 2021, 143, 3191-3204.

(13) Seo, S. B.; Lee, S.; Jeon, H.-G.; Jeong, K.-S. Dramatic enhancement of binding affinities between foldamer-based receptors and anions by intra-receptor $\pi$-stacking. Angew. Chem., Int. Ed. 2020, 59, 10441-10445.

(14) Prince, R. B.; Barnes, S. A.; Moore, J. S. Foldamer-based molecular recognition. J. Am. Chem. Soc. 2000, 122, 2758-2762.

(15) Otis, F.; Auger, M.; Voyer, N. Exploiting peptide nanostructures to construct functional artificial ion channels. Acc. Chem. Res. 2013, 46, 2934-2943.

(16) Voyer, N. Preparation of supramolecular devices using peptide synthesis: design and synthesis of a tubular hexa-crown molecule. J. Am. Chem. Soc. 1991, 113, 1818-1821. 
(17) Voyer, N.; Robitaille, M. Novel functional artificial ion channel. J. Am. Chem. Soc. 1995, 117, 6599-6600.

(18) Lin, Y. C.; Chen, C. T. Alkaline earth metal ion induced coil-helix-coil transition of lysine-coumarin-azacrown hybrid foldamers with $\mathrm{OFF}-\mathrm{OFF}-\mathrm{ON}$ fluorescence switching. Chem.-Eur. J. 2013, 19, 2531-2538.

(19) Nonokawa, R.; Yashima, E. Detection and amplification of a small enantiomeric imbalance in $\alpha$-amino acids by a helical poly(phenylacetylene) with crown ether pendants. J. Am. Chem. Soc. 2003, 125, 1278-1283.

(20) Nishimura, T.; Ohsawa, S.; Maeda, K.; Yashima, E. A helical array of pendant fullerenes on a helical poly(phenylacetylene) induced by non-covalent chiral interactions. Chem. Commun. 2004, 646-647.

(21) Kakuchi, R.; Sakai, R.; Otsuka, I.; Satoh, T.; Kaga, H.; Kakuchi, T. Synthesis and helicity induction of poly(phenylacetylene) derivatives bearing a crown cavity on the main chain. Macromolecules 2005, 38, 9441-9447.

(22) Sakai, R.; Otsuka, I.; Satoh, T.; Kakuchi, R.; Kaga, H.; Kakuchi, T. Chiral discrimination of a helically organized crown ether array parallel to the helix axis of polyisocyanate. J. Polym. Sci., Part A: Polym. Chem. 2005, 44, 325-334.

(23) Roks, M. F. M.; Nolte, R. J. M. Biomimetic macromolecular chemistry: design and synthesis of an artificial ion channel based on a polymer containing cofacially stacked crown ether rings. Incorporation in dihexadecyl phosphate vesicles and study of cobalt ion transport. Macromolecules 1992, 25, 5398-5407.

(24) Abe, H.; Takashima, S.; Yamamoto, T.; Inouye, M. Azacrown-attached meta-ethynylpyridine polymer: saccharide recognition regulated by supramolecular device. Chem. Commun. 2009, 2121-2123.

(25) Hartley, C. S. Folding of ortho-phenylenes. Acc. Chem. Res. 2016, 49, 646-654. 
(26) Kirinda, V. C.; Hartley, C. S. Folding-controlled assembly of ortho-phenylene-based macrocycles. Chem. Sci. 2021, 12, 6992-7002.

(27) Le Bailly, B. A. F.; Clayden, J. Dynamic foldamer chemistry. Chem. Commun. 2016, 52, 4852-4863.

(28) Tu, J.; Li, G.; Zhao, X.; Xu, F. Synthesis of triphenylene derivatives by Pd-catalyzed Suzuki coupling/intramolecular C-H activation between arylboronic acids and dibromobiphenyls. Tetrahedron Lett. 2019, 60, 44-47.

(29) Zhang, J.; Zhang, K.; Huang, X.; Cai, W.; Zhou, C.; Liu, S.; Huang, F.; Cao, Y. Supramolecular light-emitting polymers for solution-processed optoelectronic devices. J. Mater. Chem. 2012, 22, 12759-12766.

(30) Ashton, P. R.; Chrystal, E. J. T.; Glink, P. T.; Menzer, S.; Schiavo, C.; Spencer, N.; Stoddart, J. F.; Tasker, P. A.; White, A. J. P.; Williams, D. J. Pseudorotaxanes formed between secondary dialkylammonium salts and crown ethers. Chem.-Eur. J. 1996, 2, $709-728$.

(31) Gibson, H. W.; Jones, J. W.; Zakharov, L. N.; Rheingold, A. L.; Slebodnick, C. Complexation equilibria involving salts in non-aqueous solvents: ion pairing and activity considerations. Chem. - Eur. J. 2011, 17, 3192-3206.

(32) Perlmutter-Hayman, B. Cooperative binding to macromolecules. A formal approach. Acc. Chem. Res. 1986, 19, 90-96.

(33) Estimated from molecular mechanics calculations.

(34) Katoono, R.; Kawai, H.; Fujiwara, K.; Suzuki, T. Stereospecific change in conformation upon complexation of an exoditopic tetraamide host with a bis(ammonium) guest: chiral recognition and strong CD signaling. Chem. Commun. 2005, 5154-5156.

(35) Kuwahara, S.; Chamura, R.; Tsuchiya, S.; Ikeda, M.; Habata, Y. Chirality transcription and amplification by [2]pseudorotaxanes. Chem. Commun. 2013, 49, 2186-2188. 